\title{
Soul, mind - brain, body - what makes us the same?
}

\author{
RAFAŁ TRYŚCIEŃ \\ University of Lodz \\ rafaltryscien@gmail.com
}

\begin{abstract}
The question whether I am the same person at different moments has brought many difficulties for a long time. The problem with identity of things through time was already known in the ancient times especially when Plutarch asked whether a ship of Theseus with exchanged elements is still the same ship as before renovation. Today, we continue these considerations asking, for instance, if things, apart from their physical parts, also have temporal parts. The number of the proposed solutions to the problem of identity and identity of persons at different times resembles wandering in a dark room with a scarf on your eyes. As a result, rather than coming closer to the light switch, we find concepts which suggest that personal identity is not important, or what is important is psychological continuity or identity which is only a matter of degree. So I can be the same person as I was in some part, in some degree. It sounds like a constitution person who likes darkness and does not need light anymore. Unfortunately, first of all, we still use successfully the concept of identity in an ordinary language, and what is more, the abandonment of the notion of personal identity results in a greater number of absurdities, so in consequence, we still do not have an idea how to treat personal identity.
\end{abstract}

Keywords: personal identity; soul; complex view; simple view. 


\section{Main points}

In this article two mental experiments will be presented. The experiments were designed to sharpen two criteria of personal identity from the group of complex view, that is, the continuity of the body and the psychological continuity. The examination of these experiments will be conducted relying on the assumption that the continuity of the body and the psychological continuity are not sufficient, as the criteria of personal identity. These two criteria, the continuity of the body and psychological continuity (considered as the sum) can be examined only as a certificate of personal identity. ${ }^{1}$ The second aspect: I accept that the soul is the basic element of personal identity, on the one hand, understood as Swinburne does, and on the other, as ability to first-person perspective. ${ }^{2}$

At the beginning I would like to underline that in this article I will not refer so much to the proposal of Lynne Ruder Baker, not-so-simple simple view (Baker 2012, 179-191). I will refer to her only in case of understanding that the basis of personal identity is the human ability to first-person perspective which, in my point of view, is located in the soul. However, using the proposition of Swinburne, I recognize that the human soul is the principle of personal identity and may be the subject of further analysis, in terms of both functional as well as ontological status. ${ }^{3}$ Nevertheless, I accept that its ontological status is still a challenge and the weakest point in the discussion of the soul.

According to the view expressed by R. Swinburne. (Swinburne 2001, 329-345).

2 However, proposed solutions do not sound original, so my aim is not to be so original as to try to connect this what we know about personal identity and present the view that we can somehow still hold conceptions using the existence of the soul in time when all data are trying to prove that there is nothing more than physics and brains. On the other hand, maintaining that the soul is a source of first-person perspective requires the rethinking of the notion of Lynne Ruder Baker on not-so-simple view concept and her other works. (See: Baker 2000; Baker 2012; Baker 2013).

3 For example, by the negative statement that it is something non-material, different from the body, which is non-destructive with the death of a person. 


\section{Two questions}

Basically, the discussion devoted to looking for a necessary and sufficient criterion of personal identity is reduced to two fundamental questions: 1) what does it mean, that the person $\mathrm{O}_{2}$ in the moment $t_{2}$ is the same person as the person $\mathrm{O}_{1}$ in the moment $\mathrm{t}_{1}$ and 2) How do we know that a person $\mathrm{O}_{2}$ at the time $t_{2}$ is the same person, as $\mathrm{O}_{1}$ at time $t_{1}$ ? (Swinburne 2001, 200; Noonan 2003). These two questions we can supplemented by an auxiliary question, which can also be treated as a starting point in the discussion if criteria of personal identity must be physical. ${ }^{4}$ We cannot forget that the distinction between two questions about identity in terms of synchronic and diachronic approach, should not be considered as appearing in "two separate versions: diachronic and synchronic. There are rather two kinds of situations that raise questions of identity and diversity entities, including the people" (Bremer 2007, 28). It follows that studies concerning exploring necessary and sufficient conditions of the criterion of personal identity can also start with asking what makes it that I am this but not other person, or, what kind of feature or property distinguishes me from all other things. (Ayer 1965, 225-239).

\subsection{The principle of identity}

The term relevant to the topic of principles - principles of identity (identity), comes from G.W. Leibniz, who states that "every object is identical with itself" and, secondly, "nothing is identical with its opposite." "These statements should be supplemented by Leibniz Identification Principle: there can be many substances, which are no different from each other. The substances are identical qualitatively indistinguishable" (Bremer 2007, 28). The contribution of Leibniz can be extended by another statement formulating the principle of identity; in accordance with the principle of the

4 Ayer's question can be considered equally relevant because it broadens the perspective of research on the criteria of personal identity, and in this situation requires deeper analysis of the physical criteria used frequently because of the useful qualities. (Ayer 1965, 239-254). 
syntactic $-\mathrm{A}=\mathrm{A}$ "no matter what the $\mathrm{A}$ is, where (i) $\mathrm{x}=\mathrm{x}$ is proven logically for all $x$, or where (ii) $p$ is materially equivalent with $p(p=p$, regardless $p)$ it is proved in all p. ${ }^{5}$ (Bremer 2007, 28). Therefore, identity and personal identity need to be understood in a way that there is no other object which the object A would be the same with, but only with itself. Secondly, at the time $t_{1}$ the object $A$ as well as at time $t_{2}$ object $B$ are the same objects.

\subsection{The criteria of personal identity}

Usually, it is argued that personal identity is either something original, simple, irreducible to any other criteria ${ }^{6}$ or personal identity depends on the continuity of the body, psychological continuity, e.g. continuity of memory, character and mental states. ${ }^{7}$ In addition, in case of the second group at least more can be mentioned, or where it is said that personal identity depends on factors available in the empirical perception or reduction is required, namely a reference to e.g. a non-physical being. Having in mind that the purpose of research on personal identity is to find a criterion which will be compliant with the necessary and sufficient condition, following Grygianiec we can distinguish the following positions which will be discussed in the remaining part of the work (Grygianiec 2007, 123-128):

5 Bremer in his discussion on the principle of identity and reference to its various types mentions M. Heidegger. Heidegger, following Bremer, maintains that the sentence about identity says something more than just that each thing is identical with itself. "Syntactic $\mathrm{A}=\mathrm{A}$ says nothing about the sense of identity, which does not consist in the fact that each object is the same, but the fact that each of the same objects is the same to itself, which means that each sentence about identity expresses some mediation or synthesis. The sentence of identity is therefore not equal with two terms or the empty identity of each object, but a kind of mediation. In this way, it is not only the basic principle of thinking, but the principle of being. Something that could be the same, just one thing, you do not need two as the equality. Thus identity appears as one of the current problems in the mediation. Understanding presented by Heidegger is compliant with identity referred to the person (the person themselves is the same)." (Bremer 2007, 28-29).

6 The group of these answers is called the Simple View and it starts with Thomas Rieda and Josepha Butler.

7 The group of these answers is known as the Complex View and it starts with D. Hume and J. Locke 
(A) physical positions:

a. The identity of persons relies on identity of their bodies;

b. The identity of persons relies on the physical continuity of their bodies;

c. The identity of the person relies on identity of living organisms;

d. The identity of persons relies on the identity or continuity of their brains;

(B) Psychological positions:

a. The identity of persons relies on identity of their memory or part of the memory;

b. The identity of persons relies on their psychological continuity.

(C) Dualistic positions: the identity of persons is identity of their souls

(D) Simplistic position: the identity of persons is irreducible to other kind of relations, facts.

\section{Vagaries of personal identity}

We can imagine ourselves, citing a well-known thought-through experiment prepared by Derek Parfit, that a person wins a space trip from planet X to planet $Y^{8}$. Spaceflights are completely different than today as we could have expected, because we do not need any complicated spacecraft, we need to use only the teletransporter cabin. The teletransporter's function lies in the fact that when there is a person in the cabin, their body, including the brain, and all data, and memories are rapidly scanned and next completely destroyed. On the other hand, based on scanned information, including information even on the state of the smallest cell in a matter of seconds, the person is recreated on planet Y. Excellence of teletransporter is expressed even in the fact that when I am standing on planet X, thinking that it is snowing outside, I - who will be recreated on planet $\mathrm{Y}$ - will be thinking

8 The experiments with teletransportation and transfer of brain are chosen because of the attention coming from thought experiment and personal identity, (Coleman 2000, 53-69). Coleman observes that the text related to personal identity, which would not take into consideration these experiments would be incomplete. 
exactly the same thought perhaps my observations will be quite different. There is, therefore, no difference between a person who is subjected to teletransportion through the complete destruction of a body on planet X, a reconstructed version of the person on planet $Y$. The fundamental question is if I am the same person that I was on planet X, and now I am on planet Y.

Proponents of the sufficiency of the body theory might have some doubts. On the one hand, it is true that both persons on planet $\mathrm{X}$ and on planet $\mathrm{Y}$ appear completely indistinguishable from each other and the fact is that anywhere in the universe there is simply no other person with the same cell system, with the same looks, that could be me.. On the other hand, can we say in that in this case we are dealing with exactly the same person? Is the preservation of the continuity of exactly the same substance and the person numerically identical? This is the problem of continuity of the body, that in the presented case does not occur. There is no numerical identity between these two persons but only qualitative identity. ${ }^{9}$ Annihilation of the person on planet $\mathrm{X}$ and their perfect copy reproduction on planet $\mathrm{Y}$ results in their loss of numerical identity and the interruption of bodily continuity. The person reproduced on the planet $\mathrm{Y}$ is just a perfect copy which has the same body as the person on planet $\mathrm{X}$, but it is not the same person. ${ }^{10}$ Despite the similarities, there are already two persons, person from planet $\mathrm{X}$ no longer exists.

9 Parfit demonstrates the difference between the qualitative and numerical identity using the example of billiard balls. When we have two white balls one can say that they are identical, but only in terms of what they look like, their outer garments, because they are not the same balls. On the other hand, when the same white ball is repainted red, one can say that we have the same ball, numerically, although the quality is no longer the same. (Parfit 2012, 244).

10 Bremer remarks on the possibility of existence of perfect copy: "persons and their exact copies (ie. the zombies) are indistinguishable in terms of external properties, which they are entitled. They differ only in terms of relationship to something third (eg. to the states subjective, to the position in time and space). Thus, the identity cannot be justified only as the sum of the external properties but must also have quite specific reference to something else. This assumes that the feature remains unchanged, no matter whether it is a conscious person, or the zombies. Man can change (i) or when will change the criteria by which it is identifiable, become useless, or the lack of criteria to determine the identity, (ii) when you change the existing criteria for the identification (cf. derived from Locke's example of shoemaker becoming a prince)." (Bremer 2007, 30). 
Secondly, following Parfit's extended version of this mental experiment, we can imagine a situation in which it would appear that the scanner while it is scanning me breaks down. Rather than destroying the person on planet $\mathrm{X}$ and restoring its perfect copy on planet $\mathrm{Y}$, the scanner did not destroy a person from planet X. ${ }^{11}$ After leaving the teletransporter I decide to make a phone call to planet $Y$ to talk with my perfect copy. Will it be a conversation with myself or rather will it be a conversation with a separate entity? Right now, we are in a situation where we have two persons with the same body and exactly the same memories, namely the existence of an extreme similarity. Although nothing changes the mere fact of having the same memories also turns out not to be enough.

In the context of this experiment someone could say that what is sufficient to maintain the continuity of identity is psychological continuity. I am the same person, because it is a continuity of my memory, and it means that I remember my past events and their restoration in a more or less similar body is quite sufficient. However, restoration of mental life in a different body can be recognized as a strange solution, but that assumption is quite in line with the everyday observation, because it justifies changes in the physical body. I am the same person as I was 25 years ago, even though my body looks much different, because I know my story in a way that no one else can know it, I have special access to my mental life.

However, we can formulate a few arguments against this position. Assuming that I am the same person, because there is psychological continuity between a person at the time $t_{2}$ and a person at the time $t_{1}$, because I have the same memory, so it means that when I appear on planet Y in a teletransporter cabin also I must be the same person that I was on planet X.

However, my body may not be numerically the same body (including another brain) - and even in the extended version, in normal conditions my body will not be the same, because we observe inscribed change in the nature of our bodies - psychological continuity should solve the problem of identity. Unfortunately, it is possible that such a solution can create

11 Parfit also mentions this possibility. 
a so-called circularity error which was described e.g. by Grygianiec and many others who commented on Hume's bundle theory. If I am the same person because of the memory, which appears in a new body (perfect copy), I cannot be identified by psychological continuity, because the same psychological continuity is determined by its association with a particular person whose psychological continuity has to be a proof of. Memory is not a collection of information that is necessarily assigned to a person. The person has some memories, because the person is experiencing certain events and this person is involved in them. We can imagine that memory is like a piece of data stored on your computer. This disc contains all of my memories, because I am experiencing different events and I recorded this drive, but I am not this drive, there is no reduction of me into this drive. Secondly, there is a close relationship between memory and the computer. When we look at this particular computer, we are able to predict what information it has. And now, if the disc was recorded on a computer X, then installing it on computer $\mathrm{Y}$ does not make the computer $\mathrm{Y}$ computer $\mathrm{X}$ due to the disc with a specific content (in relation to the possibility of restoration of memory in the other object/body). Here, the objection of circularity which criticizes the concept of sufficiency of memory seems to be well-grounded. ${ }^{12}$

At this point, we can imagine another experiment, (in two versions), which will have the task to bring us to answer the question whether the criterion of personal identity can be the human brain and whether the continuity of memory and holding the same brain can be treated as a sufficient and necessary criteria.

(1) In a moment, an operation of transplantation of the brain from the body of one person A to the body of another person B will take place, which in advance has been deprived of original brain. ${ }^{13}$ The operation was

12 I note at this point, that later on I will refer to Swinburne, and personal identity, that will appeal to the existence of the soul, the very existence of the soul and its functions cannot be reduced to being the subject of memory. Then, it seems, the objection is easily able to cope with the rejection of the possibility of the existence of the soul.

13 Garret refers to that experiment and he admits that the person who introduced it to a public debate was S. Shoemaker. In the original version of that experiment, one person is called Mr. Robinson and the other Mr. Brown. The created person is Mr. Brownson. (Garret 1998, 45). 
successful. We managed to transplant brain from the body of person A to the body of person B. Typical possible solutions of that experiment can be presented in the following responses:

1a person A has survived

2a person $B$ has survived

The question that should also be posed, which is the inverse of the first person who died?

$1 b$ Person A

2b Person B

Proponents of the opportunities $1 \mathrm{a}$ and $2 \mathrm{~b}$ refer to the assumption that the identity of person relies on the identity or continuity of memory based on the identity of the brain. It cannot be ruled out that compared to the option with teletransportation from planet $\mathrm{X}$ to planet $\mathrm{Y}$, the case of preserving the brain, as an important aspect of the human body ensures a certain continuity of the previous person. Assuming further argument, that the brain is the only sufficient organ, which is responsible for the preservation of memory, character and memories, we need to admit that this person still exists.

There are known examples of people who, for different reasons, require operation to remove some parts of the brain, e.g. from a few to several percent. Making dependent personal identity in the strong sense on the survival of the brain as a whole we would have to agree to a situation in which a person would lose some part of the brain, even a few percent of it to lose either part of the memory, and along with that part of the identity. However, if we accept the presented experiment that a person's identity that derived from the survival of the brain and memory is the same, we should agree that in case of death of the person, if only functions of the brain are maintained, a person can survive their own death. It turns out, that this seems just as absurd. ${ }^{14}$ More than this, in order to be consistent,

14 At this point, I am trying to say that in some option, when we accept that the most important part of person/human body is brain and we can reduce person/human being to that 
if the person as a result of brain damage was deprived of half of their brain would they be only half a person, as before the damage? Also, during the transfer of the brain from one head to another, one would say that it is not a transmitted person A's brain, but we should to say that it is a transmitted person A, who, in fact, is reduced to a brain. ${ }^{15}$

The experiment concerning brain transplantation is further complicated when we consider its extended version. (2) We can imagine that in the same operating room another surgery is performed - split brain operation and in the next step transplanting one hemisphere of the brain of person A to the body of person $\mathrm{B}$ and the other hemisphere of the brain of person $\mathrm{A}$ to person C's body. Standard solutions ${ }^{16}$ of this experiment can be presented in three options:

\section{Person A has survived as a person $B$}

\section{Person A has survived as a person $C$}

\section{Person A has survived as a person $B$ and person $C$}

This experiment can be further complicated by asking the fundamental question, whether person A died, when the brain was deprived of person A's body or person A has survived operation because of the continuity of memory / brain or the brain and memory? If we accept that the operation was successful and the person A is still alive so now which person A is it? If person $A$ has survived due to the survival of the left hemisphere as such person B, why has not survive as the person C? If, however, person A has survived due to the transfer of the right hemisphere as the person C, why have they not survived as a person B? In this situation, we are faced with trying to respond to a relatively absurd question. But it seems more reason-

part we can suppose that maintaining that part of brain will be equal to surviving death (frankly speaking it is very difficult even to say that death would be possible). Of course, this statement is problematic because it is, above all, against common sense. The next step after accepting that suggestion should be the redefinition of death.

15 As we can see, this possibility raises a lot of difficulties such as those relating to the language. If, however, we want to consistently maintain that a person is reduced to the brain, so, we should say that in the body is a person-brain, and not that the person is a whole, along with his body.

16 Proposed by Parfit. 
able to assume that if the operation was successful, person A has survived as a person $\mathrm{B}$ and person $\mathrm{C}$, which continue their mental life. And then:

The head of person $B$ is person $A$, The head of person $C$ is person $A$, but the head of person $B$ is not the same head as the head of person $C .{ }^{17}$

And therefore person A could not survive neither does person B nor person C (see Grygianiec 2007, 126).

In this situation, we come back to the basic question, whether person A has died? If yes, then in spite of the successful transfer of the two hemispheres to two different bodies, person $B$ and person $C$ are not the same person, despite the psychological continuity. Person A has not survive the operation. If we assume, however, that person A has survived operation, because the operation was successful, we should start looking for the right answer from the beginning (Grygianiec 2007, 126).

In the proposed solutions we tried to answer the question concerning personal identity from the perspective of psychological or bodily continuity - person $\mathrm{O}_{1}$ in moment $t_{1}$ is the same person as $\mathrm{O}_{2}$ in moment $t_{2}$ because of psychological or bodily continuity. However, there is also the possibility that the criterion of personal identity necessarily and sufficiently depends on at least two criteria, e.g. the continuity of the body and the psychological continuity. And so it happens because of the separate insufficiency of two of those different criteria. S. Shoemaker who is aware of the difficulties generated only by accepting psychological continuity agrees that "regardless of whether the memory is a necessary and sufficient criterion for personal identity, or is not, it does not constitute, as it turns out, the only criterion. [...] The memory could not be the only criterion that we use saying about

17 Lynn Ruder Baker proposes her solution, which she calls not-so-simple Simple View: “There are not just two possible answers, but three possible answers to the question: which is the original person? The answers are either Lefty, Righty or neither, and the not-so-simple Simple View is compatible with all three answers. We do not know which is the correct answer, but the not-so-simple Simple View implies that there is a fact of the matter that depends on whether Lefty or Righty or neither has the original person's first-person perspective." (Baker 2012, 184-185). In this article I will refer to Baker's conception, only when it is necessary 
other persons." (Shoemaker 2001, 200). If anyone remembers any past event it is because that person was a witness to this event, when it occurred (Shoemaker 2001, 201). And being a witness of an event means that someone was present there also in the body. "At least in certain circumstances, the identity of the body must be a criterion of personal identity." (Shoemaker $2001,204)$ In addition, in determining whether a person is really present when some event takes place, or if we wish to verify if that person tells the truth, "we cannot use memory as our criterion of personal identity, and it is hard to see something else which we could use in this respect apart from the identity of the body." (Shoemaker 2001, 204-205). ${ }^{18}$

The proposed solutions are not the only ones where we try to cope with the problem of personal identity. On the one hand, continuity of the body, on the other, the psychological continuity or two of these criteria taken together reduce the identity to facts of another kind. John Robinson says that last decision in the case of preservation of identity has quaint, additional facts, which is responsible for the fact that I am this and not another person. ${ }^{19}$ (Robinson 2001, 215) Psychological continuity and bodily continuity, considered as relevant by Shoemaker or Ayer are inadequate, according to Robinson, for the preservation of personal identity (Robinson 2001, 215). That additional fact, as it is called by Robinson, may be the answer to the question of the criterion of personal identity. This is not the continuity of the body or psychological continuity determining the type of response to the question of personal identity, and this quaint additional fact (Robinson 2001, 215).

Similar concepts can be found in the texts of Swinburne who openly states that this what other philosophers, proponents of complex view theories, treat as personal identity criteria, denotes bodily continuity or psychological continuity (things that are observable) which Swinburne

18 This view is shared by Ayer, who adds that in the case of synchronous identity we could also think about support of this criterion.

19 Of course, the mere fact that the cells of my perfect copies will only be perfectly similar to me, but will not be numerically the same cells - and this is seems to be justified - which makes me numerically the same person. 
treats only as a certificate of personal identity (Swinburne 2001, 341-342). Personal identity depends on another fact which has no relation to the empirical conditions - substantial soul. Soul is a different thing than body as it is in substantial Cartesian thought and cannot be proceeded in further explanation and analysis. Identity is something original and irreducible (Swinburne 2001, 338), as it was also presented by Butler in his work Of Personal Identity.

Agreeing that the principle of personal identity is soul also solves very important issues with the possibility of the resurrection. While we are convinced that the human body is decomposed after death and the same happens to brains, which store personal memory, we must accept that a non-material, substantial and immortal ${ }^{20}$ soul provides the possibility of existence of individuals after death. Swinburne underlines the fundamental fact concerning our ideas about resurrection. In the resurrection (my resurrection) it does not matter that I can rise from the dead as well as the person who is absolutely identical with me. What counts for me is only that exactly I will rise from the death. That quaint additional fact, soul, according to Swinburne, ensures that we can survive our death. The adoption of the existence of the soul also meets the requirement mentioned by Locke (Locke 1964, 155-163; Locke 1955, t. 1) that if I exist after death, that there must be still one and the same substance, which will have no two origins in time ${ }^{21}$. The survival of me demands continuity once being launched / the substance. ${ }^{22}$

Although we can find many advantages of accepting soul as a criterion of personal identity, we also should mention a number of arguments against that crucial for that article solution. First of all, the concept of the soul has

20 I distinguish between immortality of the soul and indestructibility. However, this assumption will not be further explained because of its deep base of a religious nature that could require another article, written from a philosophical point of view.

${ }^{21}$ For example, a person in the example with teletransportation has two beginnings in time. The moment when the person on planet $\mathrm{Y}$ has their own beginning in time is the moment when the person on planet $\mathrm{X}$ is annihilated.

22 Similarly, Th. Nagel observes that in the discussion on personal identity we have to choose between the material brain and immaterial self. The transformation of the self as separate from the body or a substance may give us life after death. (See Nagel, 1995, 168). 
no overall merit of explaining in modern science. (Grygianiec 2007, 127) Science does not examine the soul, because firstly, science should prove that the soul exists according to its own methods. So far we have not discovered any proof that could be generally accepted as a valid one to the existence of soul. Secondly, the exact meaning of the soul is not known, which could be analyzed and, in fact, the concept of the soul explains nothing, because, in the familiar understanding, we can replace it with other empirically verifiable concepts. (Grygianiec 2007, 127)

While the first argument can be regarded as important and valid, because actually science does not deal with the concept of soul, nor with soul transplantations, the second argument can be avoided for several reasons. While it is true that some mystics such as St. John of the Cross or St. Teresa of Ávila explained the functioning of the memory of the person through the concept of the soul, modern science attempts to determine the exact place of memory in the brain. Unfortunately, however, it has been unknown until now. Secondly, there are cases of people who undergo a surgery of removing parts of the brain, which does not result in a loss of similar part of the memory. ${ }^{23}$ But still, we can adopt the proposition that the soul is somehow related to the brain and the soul is essentially the principle of personal identity. ${ }^{24}$ It can be proven that there is no satisfactory criterion of personal identity as a result of the reduction of identity to body or psychological continuity - so apart from the pragmatic side using an identity term, soul, as this part assigned to the person (as Thomas Aquinas did) can be as well the principle and individuation responsible for the characteristics of the species. In addition, the soul understood in such a way would be entelechy of the body, thus animating and organizing the functioning of a living human

${ }^{23}$ Removing $5 \%$ of our brain does not mean that we are removing $5 \%$ of memory. However, possible problems with memory are explained by other medial theories and this does not always mean that the main reason is in removing of physical organ. On the other hand, losing memory does not always mean that someone has lost physical brain. Also, modern science is willing to say that memory depends on using all the neurons rather than a specific part - especially physical memory.

24 The explanation of the relationship between soul, brain, and body of a person goes in a similar manner to explain the dependence of consciousness on the brain - the exact theory that could successfully explain this relationship is still unknown. 
being. ${ }^{25}$ It is particularly important that the soul can be treated as a source of the first-person perspective. While neuroscience tries to point out the importance of the brain in the construction of consciousness, the soul is the ability of the body to adopt the first-person perspective.

However, to some degree, we can accept that the adoption of the soul, which would be only something that explains the identity, generates more difficulties than benefits in solving the problem. The key difficulty concerns the access and the ontological status of the soul. At the moment, it is rather something that is being postulated rather than a fact, which would have access and its status is defined especially in a negative way. But in spite of this, its existence can be established because of the list of benefits resulting from the use of it. At this point, it is necessary to note that the soul would be understood as a matter of substance, which is in a close relation with our body and is the foundation of our existence - soul is something necessary. The body, however, the way it is organized, external features would be only a contingent fact in relation to the soul.

\section{Towards settlement}

Searching for answers to the criterion of necessary and sufficient personal identity, we encounter many obstacles. None of the known theory appears to be sufficiently satisfactory. Strictly speaking, the objects of the real world are subjects of change, and do not keep identity in time in a strong sense. Replacing parts of the molecules in the human body violates the logical principle of identity of the same with itself. On the other hand, we call the same objects identical, despite the changes that we observe in persons. We use the same name to address if not only for pragmatic reasons, but also because something in them must be the same in time. Otherwise, in the world in which there are permanent changes, we should question the existence of time and changes over time (Grygianiec 2007, 283).

25 It is possible to understand the soul as life giving breath called entelechy, the term which we can find in the Bible. 
At this point we can raise the decisive question, which theory deserves to be called the most accurate. Should we accept any of the concepts that reduce personal identity to the facts of a different kind (as Shoemaker or Ayer do) or should we state that personal identity is something original, irreducible and reject any attempts of talking about personal identity, as Butler and Ried do and Robinson and Swinburne continue (also in a dualistic version where soul is treated as a principle of personal identity)?

Following Dennett (Dennett 2015, 124-125) it can be said that reducing personal characteristics only to the brain is insufficient. When it comes to the example of memory, it turns out that any loss of part of the brain does not result in the loss of part of memory, it is not known accurately where memory is located. It would be more appropriate in this case, to explain that memory is the ability to keep our nervous system information in the form of memory traces called engrams (this theory comes from Zielinski.) He claims that an engram is "a permanent change in the nervous system caused by the temporary agitation and read as a representation of certain sensations, experiences, elements of internal and external environment"(Vetulani 2011, 183-186).

Furthermore, a lot originates from considering the concept of personal identity in the light of the possibility of resurrection ${ }^{26}$. If we want to build the concept of criteria for personal identity, which will be broad enough, it must take into account the proposition of a possible resurrection and, indeed, we must look for a factor that survives death (depending also on how death itself is understood). ${ }^{27}$ Locke's idea is very important if we talk

${ }^{26}$ At this point, my intention is to underline a very important aspect that if we reflect on the concept of resurrection we should decide what kind of resurrection we have in mind taking into consideration religion or philosophy. I will try to reflect on the conception according to its essence, namely a Christian conception. I maintain that the concept of resurrection is about the possibility of resurrection and action of God, who can restore person to life.

27 I maintain that the criteria of personal identity can be divided into two groups, apart from a typical division into the Complex View and Simple View, we can also talk about the criteria in time and criteria beyond time. The first group of criteria will address the issues of being the same person in the real world until death. The second group of criteria is about being the same in the real world and the possibility of resurrection. In case of the second group we need a criterion of personal identity, which will take into account such facts as 
about the substance identity - not only as quality, but above all as numeric. Parfit observes, that substance cannot have two origins in time. It seems, therefore, that the most appropriate solution is a perspective of Robinson, Swinburne or Butler. There is some additional fact (the soul) and physical criteria of personal identity are only the evidence of personal identity. Following this path we provide a numerical identity (always the same substance) with qualitative identity (numerically the same substance is able to reproduce the object - the body - with the same characteristics as before its death - for example, because possessing strictly the same information).

However, it is undisputable that if we all agree that life after death exists, in accordance with the principle of better to exist than not to exist because it pays off to believe in it and for rational people life after death should be a life goal. For this, we require a method to survive death, we need some type of media. It appears that the media, perhaps unfortunately for the history of this concept is called the soul. On the other hand, what is the major objection is the ontological status of the soul, we cannot imagine or describe anything about the existence of soul that can be proven by science. In fact, we do not have any access, which is based on scientific evidence or scientifically proven, to the confirmation that the soul exists.

Finally, we can imagine a case in which a person A suffers from a serious accident. The person goes to hospital and it turns out that the accident was so severe that the person irretrievably lost all their memory. What is more, this person lost all their acquired abilities (due to the sustained brain injury), such as speech, walking, etc., and recovers after about one year of rehabilitation. All the efforts of the family to help this person regain their former identity seem futile. Showing photos does not help. The fact that the person sees a picture of someone who has their body does not mean that person A feels any connection with that person. What this person has is

the destruction of the physical body, the possibility of memory loss with the destruction of the brain (only if it is in 100\% proven that memory depends only on the brain) and the possibility of resurrection. Secondly, nowadays, people who are trying to push through a dualistic or simplistic concepts or usually assume that previously there was the possibility of resurrection. Adding the possibility of survival after death, somewhat inevitably imposes the necessity of the existence of a factor that will resist death. 
only their first-person reference to themselves, which determines that the person feels who they are. Bodily continuity was saved but psychological continuity was irretrievably destructed as a result of the accident. Instead of continuing existence, we meet a new person, with old body, as we can agree. That situation is similar to the problem of teletransportion. What does not allow us to accept that in case of teletransporter corruption we deal with one and the same person is a particular fact in case of the person from planet $\mathrm{X}$ and the person from planet $\mathrm{Y}$ who will think that they are not the other person. The person from planet $\mathrm{X}$ and the person from planet $\mathrm{Y}$ will be convinced they are themselves. They can say that they have the same memories, the same body, but the reference to themselves will be of a special kind. Their own copy will not be treated as a duplicate, but as a second, completely different person. Exactly the same solution should be adopted for the allocation and transplant hemispheres to two different bodies. Person B and Person C will not be the same person. For those who question the operations of who they are, one and the other will respond first of all, it is you, and may have similar memories of similar experiences, even similar body. They will not say, however, that a person B is a person $\mathrm{C}$ or person $\mathrm{C}$ will not say they are the person $\mathrm{B}$.

In this article, I tried to more or less accurately present a concept of personal identity. This concept takes into consideration the disadvantages that result from relying only on metaphysical criteria, particularly with regard to such factors as the continuity of the body or psychological continuity. In the case of the proposal, which says that the continuity of the body and the psychological continuity are the two criteria that support each other, the concept presented in this article acknowledges them, but does not treat them as criteria. Following the view of Swinburne, they are regarded as a testimony of personal identity. The essence of personal identity comes down to the soul. On the other hand, the soul is primarily the ability of a person to gain the first-person perspective. The concept, which was presented at this point is trying to unify three modern positions - view complex, simple view and not-so-simple simple view. 
Nevertheless, proposed solution cannot be treated as a wonderful new theory that will solve all problems. Also, it is not as original as we could expect. Apart from all difficulties, proposed solutions should be under further investigation. First of all, we have to concentrate more on solving the ontological status of the soul (sometimes it seems impossible to complete) and recognize how it is possible that soul is the source of the first-person perspective and that this perspective is very closely related to the brain activity (which looks similar to the body-mind problem).

\section{Bibliography}

Ayer, A.J. 1956. The Problem of Knowledge. Cited by: Ayer, A.J. 1965. Problem poznania.

Traslation E. Koning-Chwedeńczuk. Warszawa: Wydawnictwo Naukowe PWN. Baker, L. R. 2000. Persons and Bodies A Constitution View, Cambridge University Press. Baker, L. R. 2013. “Can Subjectivity be Naturalized?” Metodo. International Studies in Phenomenology and Philosophy, Vol. 1, n. 2.

Baker, Lynne Rudder. 2012. "Personal identity: a not-so-simple simple view." In Personal identity: Complex or Simple? Edited by George Gasser and Matthias Stefan, 179-191. Cambridge University Press.

Bremer, J. 2007. Osoba - fikcja czy rzeczywistość? Tożsamość i jedność Ja w świetle badań neurologicznych. Kraków: Wydawnictwo Aureus.

Butler, J. 1975. "Of personal identity.” In Personal Identity. Perry, J. Berkeley, Los Angeles, London: Berkeley, Los Angeles, London: University of California Press.

Coleman, S. 2000. "Thought experiments and personal identity." Philosophical Studies 98: 53-69. Netherlands: Kluwer Academic Publishers.

Dennet, D. 2013. Intuition Pumps and Other Tools for Thinking. Cited by: Dennnet D. 2015. Dźwignie wyobraźni i inne narzędzia do myślenia. Translation Kurek Ł. Kraków: Copernicus Center Press.

Garret, B. 1998. Personal identity and self-consciousness. London and New York: Routledge.

Grygianiec, M. 2007. Identyczność i trwanie. Studium ontologiczne. Warszawa: Wydawnictwo Naukowe Semper.

Locke, J. 1689. An Essay Concerning Human Understanding. Cited by: Locke, J. 1955. Rozważania dotyczq̨ce rozumy ludzkiego. T. 1. Translation B. J. Gawecki. Warszawa: Wydawnictwo Naukowe PWN. 
Locke, J. 1964. "The Identity of the Man and of the Person." In Mind and Death, edited by A. Flew, 155-163. London: The Macmillan Company, New York, Collier- Macmillan Ltd.

Nagel, Th. 1995. „Umysł i ciało.” In Filozofia umysłu, edited by Chwedeńczuk B., 153-183. Warszawa: Fundacja Aletheia.

Noonan, Harold W. 2003. Personal Identity. London: Routledge.

Parfit, D. 1984. Reasons and Persons. Cited by: Parfit, D. 2012. Racje i osoby, Translation W. M. Hensel, M. Warchal. Warszawa: Wydawnictwo Naukowe PWN.

Robinson, J. 1988. Personal Identity and Survival. Cited by: Robinnson, J. 2001. „Tożsamość osobowa a przetrwanie.” In Filozofia podmiotu, edited by Górnicka-Kalinowska J., 211-223. Warszawa: Fundacja Aletheia.

Shoemaker, Sydney S. 1959. “Personal Identity and Memory,” The Journal of Philosophy Volume 56, Issue 22. Cited by: Shoemaker S., Tożsamość osobowa a pamięć, Translation. Wieczorek R., in: Filozofia podmiotu, edited by Górnicka-Kalinowska J. Fundacja Aletheia, Warszawa 2001

Swinburne, R. 1974. Personal identity. Cited by Swinburne, R. 2001. „Identyczność osoby." In Filozofia podmiotu, edited by Górnicka-Kalinowska J., 329-345. Warszawa: Fundacja Aletheia.

Vetulani, J. 2011. Mózg: fascynacje, problemy, tajemnice. Kraków: Homini. 